\title{
Reabilitação audiológica em pacientes idosos
}

\author{
Auditory rehabilitation in elderly patients
}

\author{
Mariana Ribeiro de Almeida ${ }^{1}$, Ana Cristina Guarinello
}

\begin{abstract}
RESUMO
Objetivo: O objetivo deste trabalho é comparar o perfil dos idosos que participaram de sessões de aconselhamento após a aquisição da prótese auditiva em um centro auditivo de Curitiba (PR), com aqueles que não retornaram após a primeira ou segunda sessão de aconselhamento. Métodos: Fizeram parte deste estudo 45 idosos com presbiacusia que adquiriram prótese auditiva em um centro auditivo de Curitiba (PR). A amostra foi dividida em dois grupos: o Grupo 1, Controle, composto por 30 idosos que participaram de cinco sessões de aconselhamento após o recebimento da prótese, e o Grupo 2, Experimental, formado por 15 idosos que participaram somente da primeira e/ou segunda reunião de aconselhamento. Foram utilizadas as perguntas do protocolo de entrevista inicial, para o levantamento dos dados. Resultados: Foram encontradas diferenças entre o perfil do Grupo 1 e do 2 . Dos 11 aspectos levantados, houve diferenças em oito deles, no que se refere a: antecedentes familiares de perda auditiva, usuários antigos de aparelhos auditivos, grau da perda, estado emocional, relacionamento familiar, vida social, privações decorrentes da deficiência e habilidades de manuseio da prótese auditiva. Conclusões: O estudo mostra que o grupo que participou de todas as sessões tem um perfil diferente daquele que só participou do primeiro e/ou segundo encontro, sendo que os aspectos levantados parecem ter influenciado na decisão dos integrantes do segundo grupo de continuar as sessões de aconselhamento.
\end{abstract}

Descritores: Saúde do idoso; Presbiacusia/reabilitação; Perda da audição

\section{INTRODUÇÃO}

Estudos demográficos apontam que, de 1900 até nossos dias, a expectativa média de vida aumentou 20 anos; consequentemente o número de pessoas idosas cresceu mundialmente. Por isso, o número de pesquisas e programas para atender essa população está apresentando uma elevação considerável, sendo que grande parte dos trabalhos tem o intuito de investigar o processo biológico do envelhecimento e seus problemas psicossociais $^{(1)}$.

A perda auditiva neurossensorial é uma consequência frequente do processo de envelhecimento. Essa deficiência é uma das muitas privações sensoriais que o indivíduo idoso apresenta com o envelhecimento do organismo e é uma das três condições crônicas mais prevalentes, ficando atrás somente da artrite e da hipertensão(2).

Trabalho realizado na Universidade Tuiuti do Paraná - UTP - Curitiba (PR), Brasil.

(1) Especializanda em Audiologia Clínica pela Universidade Tuiuti do Paraná - UTP - Curitiba (PR), Brasil; Fonoaudióloga do Centro de Audição e Linguagem - CEAL - Curitiba (PR), Brasil.

(2) Doutora, Professora do Curso de Graduação em Fonoaudiologia, da Especialização em Audiologia Clínica e do Mestrado e Doutorado em Distúrbios da Comunicação da Universidade Tuiuti do Paraná - UTP - Curitiba (PR), Brasil.

Endereço para correspondência: Mariana Ribeiro de Almeida. R. Martim Afonso, 2416/802, Curitiba - PR, CEP: 80730-030. E-mail: mariwats@hotmail.com.

Recebido em: 4/7/2008; Aceito em: 12/11/2008
As alterações auditivas decorrentes do processo de envelhecimento recebem o nome de presbiacusia, que se manifesta como uma perda auditiva bilateral coclear progressiva de grau e severidade variável a cada indivíduo ${ }^{(1)}$. Essas alterações auditivas ocorrem em função de uma série de distúrbios somáticos que atingem a orelha interna, degenerando o órgão auditivo.

Os idosos que apresentam presbiacusia experimentam uma diminuição da sensibilidade auditiva e uma redução na inteligibilidade da fala, o que vem a comprometer seriamente o seu processo de comunicação verbal. A perda auditiva, quando afeta os sons agudos - de alta frequência - torna a percepção das consoantes muito difíceis, especialmente quando a comunicação ocorre em ambientes ruidosos ${ }^{(3)}$.

Assim, cabe ressaltar que alguns autores, em seus estudos sobre a autopercepção do handicap em deficientes auditivos adultos e idosos, chamaram a atenção dos profissionais de áreas afins, com relação às implicações psicossociais da deficiência auditiva na vida dos indivíduos ${ }^{(4)}$. Para esses pesquisadores, a deficiência impede ou limita o seu portador de desempenhar plenamente o seu papel na sociedade, sendo assim uma das condições mais incapacitantes. Consequentemente, isso gera uma série de sentimentos negativos e de inferioridade, quadro que piora quando a deficiência auditiva se alia ao processo de envelhecimento do indivíduo, no qual uma série de mudanças biológicas, psicológicas e sociais irá acontecer juntamente com déficits sensoriais, causando isolamento e declínio na qualidade de sua comunicação. 
O declínio do status do idoso na família e na sociedade, secundário à gradual perda de energia física e produtividade econômica tende a isolá-lo e privá-lo de fontes de informação e comunicação com o mundo que o cerca ${ }^{(5)}$.

Cabe acrescentar que alguns profissionais que trabalham nessa área dispensam pouca atenção a esses pacientes, no que se refere aos aspectos psicossociais e às orientações que poderiam melhorar sua qualidade de vida. Dessa forma, então, a implantação de um programa de reabilitação global que envolveria a seleção e adaptação das próteses auditivas, auxiliaria o usuário e a família a lidarem com as desvantagens e limitações da deficiência auditiva, o que efetivamente poderia melhorar a qualidade de vida desse paciente, inserindo-o novamente no mundo de comunicação verbal.

Estudos sugerem a implantação de um programa de reabilitação, revelando que esse programa pode minimizar todas essas reações psicossociais; porém, para que isso ocorra faz-se necessária a seleção, a indicação e a adaptação do aparelho de amplificação sonora individual (AASI) inseridas em programas de reabilitação audiológica global, auxiliando o idoso portador de deficiência auditiva e seus familiares ${ }^{(6-7)}$.

Além disso, os programas de reabilitação auditiva para os idosos são importantes para ajustá-los às suas famílias e à sociedade. $\mathrm{O}$ acompanhamento fonoaudiológico os ajuda a manusear e higienizar suas próteses auditivas, bem como a se comunicar melhor em ambientes ruidosos e a reutilizar o telefone $\mathrm{e}^{(7)}$.

Assim sendo, entende-se que, além da seleção e adaptação da prótese auditiva, é extremamente importante que o paciente e a família participem de sessões de orientações, que não devem envolver somente as informações referentes ao aparelho, mas também orientações sobre as condições psicossociais decorrentes da perda auditiva.

O programa de reabilitação audiológica para o idoso deve fornecer, além do diagnóstico audiológico e indicação de AASI, um trabalho sistemático sobre reabilitação auditiva, especificando as questões sociais da perda da audição na vida do idoso ${ }^{(8)}$.

Tendo em vista a importância de um programa de reabilitação auditiva para a população idosa, o objetivo deste trabalho foi comparar o perfil dos idosos que participaram de cinco sessões de aconselhamento, após a aquisição da prótese auditiva em um centro auditivo de Curitiba (PR), com os pacientes idosos que não retornaram após a primeira ou segunda sessão de aconselhamento. A hipótese desse trabalho era de que os idosos que participam das sessões de aconselhamento poderiam lidar melhor com as intercorrências da perda auditiva e melhorar a sua qualidade de vida.

\section{MÉTODOS}

Esta pesquisa foi aprovada pelo Comitê de Ética da Universidade Tuiuti do Paraná, sob o protocolo número 074/2006. Os dados foram coletados de fevereiro de 2005 a abril de $2006 \mathrm{em}$ um centro auditivo da cidade de Curitiba (PR). Antes de participar da pesquisa, cada idoso envolvido recebeu um Termo de Consentimento Livre Esclarecido, explicando o tema do estudo, seus objetivos e sua importância. Após a leitura do termo, os que concordaram em fazer parte da investigação o assinaram.
Fizeram parte desta pesquisa 45 idosos com presbiacusia $(\mathrm{N}=45)$, da cidade de Curitiba, com idades entre 62 e 93 anos. Nenhum deles apresentava problemas graves de saúde. A amostra foi dividida em: Grupo 1, denominado Grupo Controle, composto por 30 idosos - 11 do sexo masculino e 19 do sexo feminino - que realizaram cinco sessões de aconselhamento após receberem a prótese auditiva em um centro auditivo de Curitiba (PR), e Grupo 2, denominado Grupo Experimental, formado por 15 pacientes idosos - seis do sexo masculino e nove do sexo feminino - que não retornaram após a primeira ou a segunda sessão.

Os idosos, após adquirirem o AASI, tinham a oportunidade de receber cinco sessões de aconselhamento: as duas primeiras eram destinadas à aplicação da entrevista inicial e à orientação ao paciente sobre os cuidados e o manuseio do seu aparelho; nas outras, eram fornecidas ao paciente as estratégias facilitadoras de posicionamento em conversas e de leitura orofacial, a fim de minimizar as dificuldades de comunicação e maximizar os benefícios do AASI.

O material utilizado para o desenvolvimento da pesquisa foram protocolos de entrevista inicial (Anexo 1). Esses continham dados referentes às questões auditivas dos pacientes, tais como: idade, grau da perda auditiva, lado da protetização, se era usuário antigo de prótese auditiva, modelo do aparelho auditivo, relatos do sujeito sobre a sua perda auditiva, há quanto tempo possuía a perda, causa, diagnóstico, casos de surdez na família, relacionamento familiar, estado emocional, privações decorrentes da perda auditiva, vida social, vida profissional/ ocupação, maiores dificuldades (ambientes/locais), expectativas quanto ao uso do AASI, modelo dos aparelhos (estado, descrições, habilidade de manuseio, etc.), uso de técnicas de apoio (como leitura labial), exames apresentados e/ou solicitados. Para o levantamento de dados e verificação do perfil dos dois grupos, foram utilizadas as entrevistas iniciais de cada paciente idoso de ambos os grupos.

Este estudo foi analisado quantitativa e qualitativamente. Cabe ressaltar que não foram analisadas todas as perguntas da entrevista inicial; selecionaram-se apenas as questões mais relevantes para este estudo.

Para a análise estatística dos resultados foi aplicado o teste Qui-quadrado, adotando-se o nível de significância de 0,05 $(5 \%)$. Os dados qualitativos foram descritos e comparados à literatura compulsada.

\section{RESULTADOS}

$\mathrm{Na}$ aplicação do teste Qui-quadrado, considerando-se o nível de significância de 0,05 (5\%), e N=45 (30 indivíduos do Grupo 1 e, 15 indivíduos do Grupo 2), verificaram-se diferenças estatisticamente significantes em dois aspectos, dos cinco analisados:

- No aspecto grau da perda auditiva, considerando-se para efeito do teste somente duas categorias: (leve + moderado) e (severa + profunda), o resultado foi $\mathrm{p}=0,0073$, e, portanto, significante.

- Para os dados do item vida social, a comparação resultou em $p=0,0073$. Assim, houve diferença significante deste aspecto, entre os dois grupos analisados. 
- Para o dado de habilidade de manuseio do AASI, o valor foi de $\mathrm{p}=0,0860$, portanto este resultado não foi considerado estatisticamente significante.

- Para os outros dois aspectos analisados, relacionamento familiar e ocupação/vida profissional, não foi possível aplicar o teste Qui-quadrado, pois não havia sentido em formar somente duas categorias de respostas.

O primeiro aspecto analisado diz respeito ao número de indivíduos dos dois grupos que eram usuários antigos de próteses auditivas. Verificou-se que, no Grupo 1, 73\% dos indivíduos não utilizavam prótese auditiva antes de virem até o centro auditivo e, no Grupo 2, 60\% dos entrevistados eram usuários antigos de próteses, ou seja, estavam trocando seus AASI antigos por novos.

Na segunda questão, que se referia aos antecedentes familiares com perda auditiva, verificou-se no Grupo 1 que, dos 30 indivíduos analisados, $50 \%$ relataram ter parentes com perda auditiva, e a outra metade negou antecedentes familiares. Já no Grupo 2, somente 33\% informaram que possuem casos de perda auditiva na família; os outros $67 \%$ dos idosos não têm parentes com essa deficiência.

Na Figura 1, pode-se observar que, no momento em que colocaram a prótese auditiva, $80 \%$ dos idosos do Grupo 1 apresentavam perda de grau moderado e $20 \%$ de grau severo. No Grupo 2, $47 \%$ apresentavam perda auditiva de grau severo, $33 \%$ de grau moderado, $13 \%$ de grau profundo e $7 \%$ de grau leve.

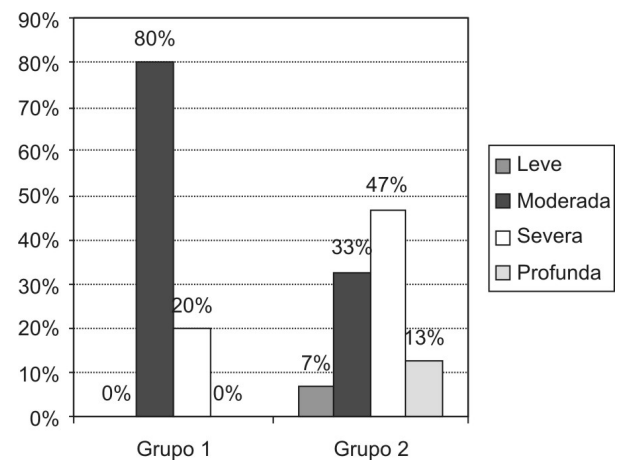

Figura 1. Grau da perda auditiva dos indivíduos

Outro aspecto do levantamento foi o lado da protetização. No Grupo 1, 50\% dos sujeitos foram protetizados na orelha direita, $23 \%$ na orelha esquerda e $27 \%$ bilateralmente. A predominância do lado da protetização dos investigados do grupo 2 foi de $53 \%$ do lado direito, $27 \%$ do esquerdo e $20 \%$, bilateralmente.

Com relação ao estado emocional dos pacientes considerou-se "bom" para os idosos que relataram se sentirem bem emocionalmente e denominou-se "alterado", para respostas contrárias. Pôde-se verificar que $87 \%$ dos idosos do Grupo Controle - que participaram das cinco sessões de aconselhamento - no momento da entrevista, consideravam-se bem emocionalmente e apenas uma pequena parcela, $13 \%$ deles se diziam abalados. No Grupo Experimental, os resultados foram diferentes, já que 53\% dos pacientes relataram que estavam bem emocionalmente e $47 \%$ responderam que não. As respostas negativas dessa pergunta eram seguidas de reclamações familiares, problemas financeiros, ou simplesmente desânimo em função da idade.

Outro aspecto levantado neste trabalho foi se os idosos entrevistados se privaram de fazer algo em decorrência de sua perda auditiva. Dos idosos do Grupo 1, apenas 33\% deixaram de fazer algo em função da perda auditiva, diferentemente do Grupo 2, em que 53\% responderam que deixaram de fazer algo por apresentar problema na audição. As privações citadas por esses pacientes foram: idas a igrejas, a reuniões, a festas, a cinemas e participação em conversas com amigos e/ou familiares.

Nos dados do protocolo "Relacionamento familiar", foi analisada a questão de com quem esses idosos conviviam. Observam-se as respostas na Figura 2.

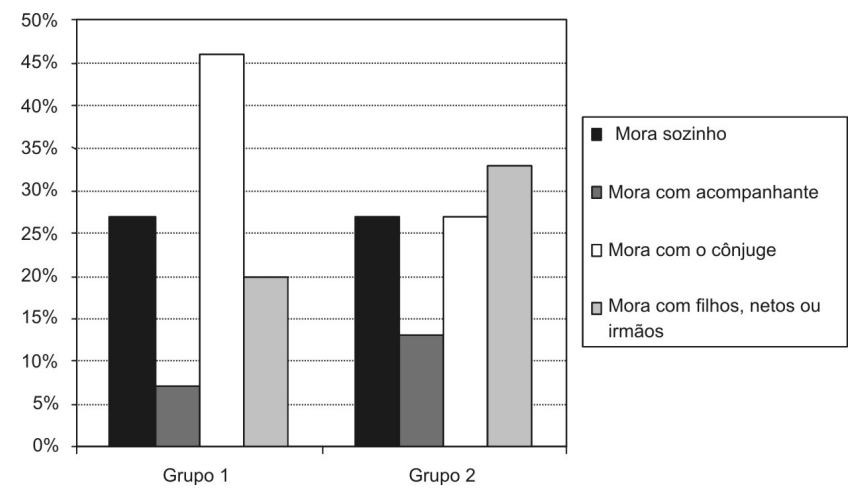

Figura 2. Relacionamento familiar

Com relação ao perfil do Grupo 1 nesse aspecto, é possível verificar que a maioria dos idosos, ou seja, $46 \%$ moravam com os cônjuges, $27 \%$ viviam sozinhos, $20 \%$ residiam com irmãos, netos ou filhos e apenas $7 \%$ dos idosos moravam com acompanhantes. Entretanto, no Grupo 2, o perfil apresentou-se diferente: $33 \%$ dos pacientes moravam com os irmãos, netos ou filhos, $27 \%$ viviam sozinhos, a mesma porcentagem, $27 \%$ residiam com o cônjuge e $13 \%$, com acompanhantes.

Com relação à questão da ocupação/vida profissional que os pacientes indicaram na época em que foi aplicado o questionário, as respostas podem ser verificadas na Figura 3.

Visualizando a Figura 3, nota-se que a metade dos indivíduos do Grupo 1, ou seja, 50\% eram aposentados e não exerciam outra atividade profissional, $23 \%$ deles eram aposentados e tinham outra ocupação profissional, $20 \%$ nunca

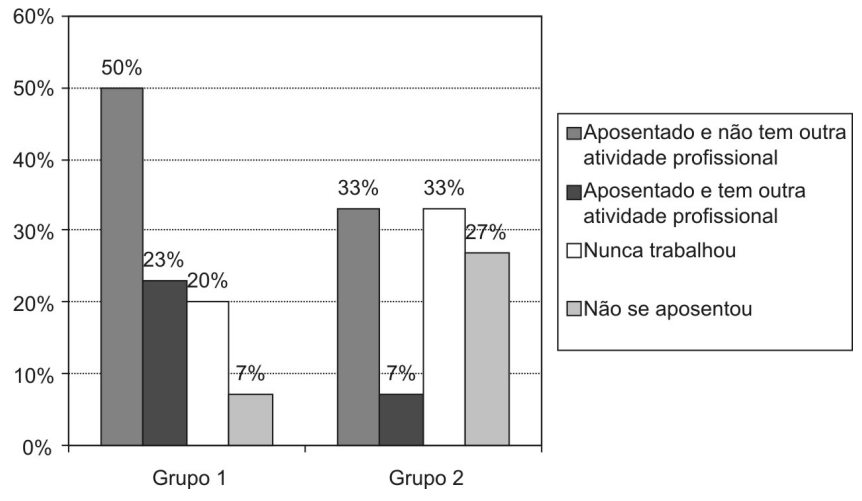

Figura 3. Ocupação/vida profissional 
haviam trabalhado, e 7\% ainda não tinham se aposentado. No entanto, no perfil do Grupo 2, observamos que, dos 15 entrevistados: $33 \%$ eram aposentados e não exerciam outra atividade profissional, $33 \%$ nunca haviam trabalhado, $27 \%$ ainda não estavam aposentados e $7 \%$ estavam aposentados, mas tinham outro trabalho profissional.

Quanto às expectativas do uso do AASI, ambos os grupos possuíam boas expectativas, ou seja, $87 \%$ dos idosos do Grupo 1 responderam que estavam otimistas quanto aos benefícios do AASI e $73 \%$ dos pacientes do Grupo 2 também tinham boas expectativas.

A Figura 4 ilustra a questão da vida social dos indivíduos dos dois grupos.

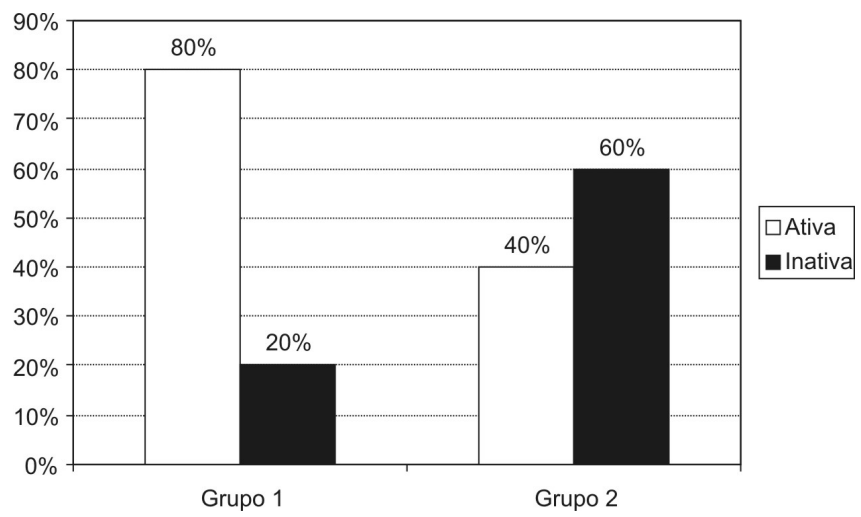

Figura 4. Vida social dos idosos

No Grupo Controle, observa-se que a grande maioria, naquela época, apresentava uma vida social ativa: $80 \%$ deles consideravam-se bem ativos, citando, por exemplo, as atividades físicas, as participações em bolões, as reuniões de amigos e/ou terceira idade. Além disso, revelaram que frequentavam os eventos da igreja: crochê, bingos, festas comemorativas. No Grupo 2, é possível identificar um perfil muito diferente, pois $40 \%$ dos idosos se consideram ativos e $60 \%$ inativos, ou seja, passavam a maior parte do tempo em casa, evitando lugares com muitas pessoas ou atividades prolongadas.

$\mathrm{O}$ último aspecto estudado em ambos os grupos foi a habilidade dos pacientes em manusear seus AASI. Na Figura 5, observam-se as respostas de ambos os grupos.

Verificou-se que $83 \%$ dos pacientes do Grupo 1 manuseavam os seus AASI, ou seja, eles colocavam as próteses

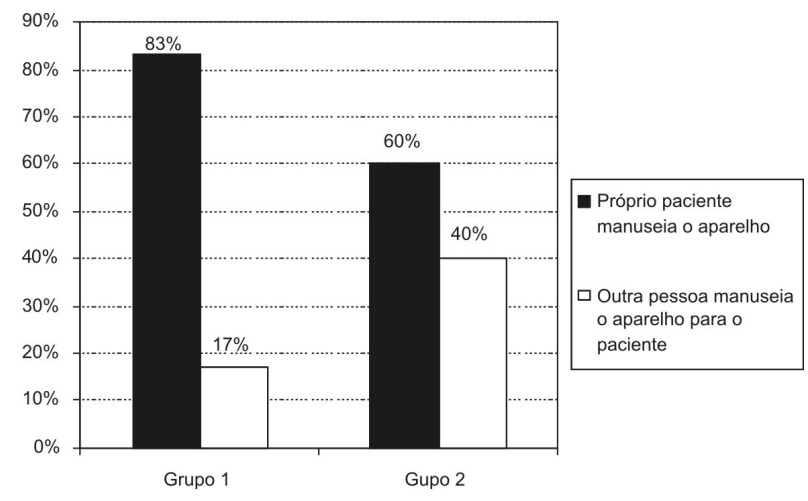

Figura 5. Habilidades de manuseio do aparelho auditivo no ouvido, trocavam as pilhas e regulavam o volume. Já no Grupo Experimental, observou-se que $60 \%$ dos idosos lidavam sozinhos com seus AASI e $40 \%$ tinham outra pessoa que fazia isso para eles (normalmente a pessoa mais próxima da família ou o seu acompanhante).

\section{DISCUSSÃO}

Observou-se nessa pesquisa que a maioria dos indivíduos do Grupo 1 nunca havia utilizado prótese auditiva, contrariamente aos integrantes do Grupo 2, no qual a maioria, ou seja, $60 \%$ já era usuária de prótese.

Esse fato pode ter sido decisivo na sua falta de interesse pelas sessões de aconselhamento, pois, provavelmente, por já serem usuários de próteses, estavam adaptados com o AASI e não acharam necessário receber novas informações sobre ele.

Cabe aqui ressaltar que, a plasticidade neural é a capacidade do tecido neural das vias auditivas centrais de reorganizar e alterar a função em resposta à estimulação auditiva. Isso leva ao efeito do uso da amplificação poder melhorar o reconhecimento da fala ao longo do tempo. Essa melhora do reconhecimento de fala, à medida que o indivíduo aprende a utilizar novas pistas de fala com o uso da amplificação, foi chamada de aclimatização. Esses benefícios não emergem imediatamente, mas após a exposição ao ambiente acústico, e aumentam com o passar do tempo ${ }^{(9)}$.

Não se pode afirmar que os indivíduos já usuários de aparelho do Grupo 2 estavam "aclimatizados" com as próteses, para esta afirmação seria necessário outro estudo. Portanto, consideramos dentro deste estudo, verificando as limitações e restrições de nossos objetivos, que os idosos já usuários de AASI estavam adaptados às suas próteses.

Apesar de os componentes do Grupo 2 já utilizarem próteses auditivas e estarem adaptados, poderiam ter um ganho maior se tivessem participado das sessões de aconselhamento, pois as estratégias facilitadoras, orientações e treinos auditivos provavelmente trariam efeitos mais rápidos e efetivos, o que possibilitaria melhora na comunicação.

Com relação aos antecedentes familiares de perda auditiva, no Grupo 2, $67 \%$ não têm parentes com perda e, no Grupo 1, $50 \%$ dos indivíduos relataram que têm antecedentes familiares com essa deficiência. Supõe-se que os idosos do Grupo 1, por terem parentes com problema auditivo, estavam mais familiarizados com as questões dessa perda e já eram mais informados a respeito das consequências da presbiacusia. Já os integrantes do Grupo 2 eram menos informados, pois a maioria não possuía parentes com esse problema; assim, esse grupo talvez devesse ter se interessado mais por todas as sessões de aconselhamento, principalmente para receberem mais informações sobre a deficiência e sobre como lidar melhor com ela.

Quanto ao grau de perda auditiva dos indivíduos do Grupo Controle e do Experimental, a maioria dos componentes do primeiro grupo apresentava perda de grau moderado, enquanto que no segundo grupo, a maior parte apresentava perda severa. Esses dados parecem sugerir que os idosos do Grupo 1 estivessem descobrindo a perda auditiva naquele momento, pois a maioria apresentava grau moderado e, no Grupo 2, a maioria apresentava uma perda severa, então esses idosos já 
apresentavam o problema há mais tempo e talvez julgassem não precisar do aconselhamento, pois já estavam habituados ao aparelho.

Com relação ao lado predominante da protetização, verificou-se que em ambos os grupos foi o lado direito e os índices de protetização do lado esquerdo e bilateralmente foram muito similares. Com esses resultados, pode-se perceber que a minoria dos idosos foi protetizada bilateralmente. Entretanto, indivíduos com deficiência auditiva bilateral, geralmente ouvem melhor com duas próteses do que com uma só. As vantagens da adaptação binaural são: melhor localização do som, somação binaural, eliminação do efeito sombra da cabeça, habilidade em separar sons de ruídos ambientais e melhor reconhecimento de fala na presença de ruído $^{(9)}$. Ou seja, todos esses itens contribuem para uma comunicação mais efetiva e, consequentemente, para a melhora da qualidade de vida dos indivíduos protetizados. As pessoas de ambos os grupos que foram protetizados de um só lado se beneficiariam da protetização binaural, principalmente as do Grupo 2, pois, como se observou, apresentavam grau de perda auditiva maior.

Cabe ressaltar que todos os pacientes do centro auditivo foram orientados sobre os benefícios e importância da protetização binaural; entretanto, alguns optaram pela protetização unilateral devido ao custo elevado de duas próteses, à experiências ruins em teste com dois AASI e por opção pessoal.

Com relação ao estado emocional dos idosos de ambos os grupos, é interessante notar que $87 \%$ dos componentes do Grupo 1 se consideravam bem emocionalmente no momento da entrevista, contra 53\% dos integrantes do grupo 2. Pode-se supor, portanto, que o fato de quase metade dos pacientes do Grupo 2 não se considerarem bem emocionalmente pode ter sido determinante na sua decisão de não participar das reuniões de aconselhamento.

Outra hipótese é a de que o estado emocional relatado pelos investigados esteja relacionado ao grau da perda auditiva. Um estudo que comparou idosos com audição normal com idosos deficientes auditivos demonstrou que a perda auditiva parece estar associada à saúde geral debilitada e está intimamente relacionada a fatores como mobilidade reduzida, bem como redução na atividade e número de saídas de casa. Além disso, esse estudo afirma que a deficiência auditiva causa uma redução significativa na interação e contatos interpessoais e parece estar associada à redução da alegria de viver (idosos deficientes auditivos têm maior probabilidade de serem deprimidos) $)^{(2)}$.

Outro dado que tem relação com o estado emocional dos idosos dessa população diz respeito às privações decorrentes da perda auditiva. Mais uma vez encontrou-se um perfil diferenciado entre os dois grupos analisados. Dos idosos que participaram de todos os encontros de aconselhamento, $67 \%$ relataram que não deixaram de fazer nada por apresentarem alteração auditiva; entretanto, mais da metade daqueles que não frequentaram todas as sessões afirmaram o contrário, ou seja, que deixaram de ir a muitos lugares e fazer coisas porque não estavam ouvindo direito. Esse dado parece ter relação com o que foi explanado sobre o estado emocional e a perda auditiva na terceira idade por outra pesquisa que afirma que o envelhecimento afeta o relacionamento social do idoso devido a fatores psicofísicos e de natureza sociocultural, desenvolvendo um processo característico de autodesvalorização e de subestima, agravado por sua dificuldade de comunicação ${ }^{(10)}$.

De acordo com os estudos citados nessa pesquisa e com essa investigação fica claro a necessidade dos idosos participarem ativamente de processos comunicacionais e de atividades sociais, além disso, os profissionais devem sensibilizar os idosos sobre a importância de receberem orientação sobre o uso da prótese auditiva.

Com relação à questão que perguntava quem morava com os idosos, verificou-se que a maioria (46\%) dos idosos do Grupo Controle morava com os cônjuges, $27 \%$ sozinhos, $7 \%$ viviam com acompanhantes e $27 \%$ com parentes. No Grupo 2, o índice de entrevistados que moravam com cônjuges foi menor que no 1: $27 \%$ de respostas. O mesmo percentual do Grupo 2 residia sozinho, enquanto que $13 \%$ deles viviam com acompanhantes, um índice maior do que o encontrado entre os componentes do Grupo 1. Constatou-se que a maioria $(33 \%)$ dos idosos do Grupo Experimental habitava com parentes. Esses parentes eram apontados como pessoas que geralmente, não tinham paciência para repetir quando os mais velhos reclamavam de que não haviam entendido o que tinha sido dito. Este fato gerava estresse na rotina diária da família. Pesquisas afirmam que, quando há algum tipo de comprometimento no sistema auditivo, uma série de dificuldades e angústias surge, promovendo desajustes sociais, discriminações e limitações ${ }^{(11-12)}$.

Dos pesquisados do Grupo 1 que frequentaram todas as sessões, foi observado que o maior índice de acompanhamento às reuniões foi o do cônjuge, o que pode tê-los motivado a participar do encontro.

Outro levantamento importante é com relação à ocupação dos idosos dos grupos estudados. A metade, ou seja, 50\% dos componentes do primeiro grupo eram aposentados e não tinham outra atividade profissional, $23 \%$ eram aposentados e tinham outra ocupação profissional, $20 \%$ nunca haviam trabalhado e apenas 7\% não havia se aposentado. Verificou-se que, no segundo grupo, o perfil é um pouco diferente: $33 \%$ eram aposentados sem outra atividade profissional e $33 \%$ nunca haviam trabalhado, porém $27 \%$ dos idosos ainda não havia se aposentado, fato que pode ter interferido no tempo disponível para irem às terapias.

A vida social dos frequentadores do centro auditivo mostrou-se diferente nos dois grupos pesquisados. No Grupo Controle, $80 \%$ tinham vida social ativa, ou seja, participavam de encontros de terceira idade, atividades sociais da igreja, festas comemorativas, reuniões familiares, com amigos etc. Esse percentual foi diferente no segundo grupo, no qual $40 \%$ dos pesquisados apresentavam vida ativa e $60 \%$ ficavam a maior parte do tempo em casa. Pesquisadores analisaram esse quadro associado à perda auditiva, afirmando que o processo de envelhecimento confronta o indivíduo com uma série de problemas pessoais e sociais e a comunicação torna-se a diferença crucial entre o isolamento e o vínculo social, entre a dependência e a independência, entre o vazio da solidão e o sentimento de ser e pertencer ${ }^{(12)}$. Os idosos do Grupo 2 parecem ter uma tendência maior ao isolamento social, provavelmente em função do problema auditivo. 
Sabe-se que portadores de presbiacusia vivenciam dificuldades profundas na esfera pessoal e social: afastamento consciente ou inconsciente de atividades anteriormente prazerosas; isolamento social, ou seja, dificuldades de interação com a família, os amigos e a comunidade; incapacidade auditiva em igrejas, teatros, cinemas, assim como diante do rádio e da TV; reações inapropriadas durante a conversação ou redução de frequência de participação em atividades de recreação ou lazer; alterações psicológicas tais como: depressão, frustração, raiva e medo devido à incapacidade de se comunicar com os outros $^{(13)}$.

Os benefícios do uso do AASI pelo idoso incluem: melhora nas relações familiares, independência e segurança; entretanto, mesmo aqueles idosos que utilizam prótese, podem ainda apresentar diferentes níveis de dificuldades de comunicação. É para esta população, que são destinados os programas de reabilitação e/ou aconselhamento ${ }^{(14)}$.

Outro dado analisado que evidencia diferença entre o perfil dos dois grupos são as habilidades de manuseio do AASI, tais como: retirar e colocar a pilha, controlar o volume e colocar o aparelho no ouvido. Verificou-se que a maioria dos sujeitos que participaram de todas as sessões (80\%) foi composta pelos que já sabiam como lidar com a prótese auditiva; enquanto que a maior parte dos que não compareceram a todos os encontros (60\%) não manipulava suas próteses.

Esses dados parecem sugerir que os idosos do Grupo 2 eram mais dependentes de outras pessoas; portanto, supõe-se que as sessões de aconselhamento seriam fundamentais para eles.

Um estudo sobre um programa de reabilitação auditiva ao idoso portador de presbiacusia já havia concluído que os esclarecimentos de dúvidas sobre essa deficiência, os cuidados e o manuseio do AASI são de suma importância, pois, com as orientações, os envolvidos passaram a ter um melhor conhecimento sobre seus problemas e sobre como superá-los, o que favoreceria o processo de reabilitação auditiva ${ }^{(6)}$.

Uma pesquisa para identificar o universo de relacionamentos interpessoais de 30 idosas, foi realizada no Projeto Capacidade da Faculdade de Saúde Pública da Universidade de São Paulo (USP). As idosas foram distribuídas em dois grupos etários: 60 - 75 anos e mais de 75 anos. Uma das conclusões mostrou que a média de componentes para as funções pesquisadas, considerando-se apenas a proximidade de relacionamento, foi pequena, ou seja, no máximo duas pessoas. Segundo a autora, este dado merece atenção especial, pois revela que são poucas as pessoas que auxiliam os idosos caso eles precisem de ajuda. Então, consideramos que esta é uma informação importante; pois é fundamental identificar as pessoas que convivem, auxiliam e cuidam dos idosos, para que estes recebam orientações e estejam inteirados das suas necessidades ${ }^{(15)}$.

Assim, se os integrantes do Grupo 2 e seus acompanhantes e/ou familiares tivessem participado de todas as reuniões de aconselhamento, poderiam ter se beneficiado com as orientações e, sentindo-se mais familiarizados com o aparelho, conviveriam melhor com o problema de audição.

Portanto, levando-se em consideração os antecedentes familiares de perda auditiva, os achados do grau da perda, o estado emocional, a vida social, as privações decorrentes dessa deficiência e a habilidade de manuseio dos AASI dos idosos do Grupo 2, verifica-se que grande parte deles não tinham familiares com o mesmo problema, que quase a metade desses indivíduos se consideravam deprimidos, a maioria já apresentava a perda auditiva, há mais tempo do que os componentes do Grupo 1; muitos não manuseavam seus próprios aparelhos auditivos, que tinham vida social inativa e, ainda, que mais da metade deles deixaram de fazer coisas em função da perda auditiva. Todos esses aspectos evidenciam uma diferença grande do perfil dos idosos das pessoas do primeiro grupo e também levam a crer que tais aspectos podem ter influenciado esses pacientes a não participarem de todos os encontros de aconselhamento.

Entende-se que, além da adaptação ao AASI, um programa de reabilitação audiológica após a protetização deve ser considerado indispensável para os pacientes, pois a presbiacusia gera nos indivíduos um distúrbio na comunicação, ou seja, compromete sua comunicação com as pessoas de seu convívio. Assim o programa de reabilitação vem para ajudá-los a minimizar esses efeitos da deficiência auditiva, tornando-os aptos a se comunicar melhor, amortecendo o impacto psicossocial profundo que esse quadro proporciona.

Sugere-se a elaboração, por parte dos fonoaudiólogos, desses programas de aconselhamento em grupos, para essa população. Essa forma coletiva é efetiva para reduzir a percepção negativa no handicap entre a população idosa. Integrando os contatos sociais às estratégias de reabilitação tradicionais pode-se aumentar o envolvimento pessoal do paciente com o seu programa de aconselhamento, motivando-o a buscar ajuda para lidar com sua perda auditiva ${ }^{(16)}$.

\section{CONCLUSÃO}

Neste estudo, procurou-se analisar o perfil dos idosos protetizados em um centro auditivo em Curitiba (PR). Diferenças significantes entre o grupo de pacientes que realizaram todas as sessões de aconselhamento, Grupo 1, e os que não participaram de todas as reuniões, Grupo 2 foram encontratadas. Dos 11 aspectos levantados, verificou-se, em oito deles, tendências diferentes entre os grupos.

Em função do que se observou no perfil segundo Grupo, concluiu-se que seus integrantes se beneficiariam muito das sessões de aconselhamento, pois eram justamente eles que precisavam de mais informações sobre a própria perda auditiva e suas consequências, de orientações sobre o manuseio do aparelho, além de orientações aos seus familiares ou acompanhantes. 


\begin{abstract}
Purpose: The aim of this study was to compare the profile of elderly people who participated in five counseling sessions after the purchase of hearing aids in an auditory center of Curitiba (PR), to that of those who did not return after the first or second session. Methods: Forty five elderly subjects with presbycusis from an auditoy center of Curitiba (PR) participated in this study. The sample was divided into two groups: Group 1, Control, composed by 30 individuals who participated in the five counseling sessions; and Group 2, Experimental, constituted by 15 individuals who participated only in the first and/or second session. The questions of the initial interview were used for gathering these data. Results: Differences were found between the profiles of both groups. From the eleven aspects raised, there were differences in eight of them, regarding: family history of hearing loss, former users of hearing aids, degree of hearing loss, emotional state, family relations, social life, deprivations arising from the hearing loss, and abilities in handling the hearing aids. Conclusions: The study showed that the group that participated in all counseling sessions presented a different profile from that who only participated in the first and/or second meeting, and that the issues raised seem to have influenced the decision of the members of the second group to continue participating in the sessions.
\end{abstract}

Keywords: Health of the elderly; Presbycusis/eehabilitation; Hearing loss

\section{REFERÊNCIAS}

1. Giacheti CM, Duarte VG. Programa de atuação fonoaudiológica junto a idosos institucionalizados. In: Lagrotta MGM, César CPHAR. A fonoaudiologia nas instituições. São Paulo: Lovise; 1997. p. 17-27.

2. Bess FH, Hedley-Willians A, Lichtenstein MJ. Avaliação audiológica dos idosos. In: Musiek FE, Rintelmann WF, editores. Perspectivas atuais em avaliação auditiva. Barueri: Manole; 2001. p. 343-70.

3. Russo ICP. Audição em idosos [Internet]. 2006 [citado 2007 Jan 12]. Disponível em: http://www.entreamigos.com.br/textos/defaud/audidos. htm

4. Corrêa GF, Russo ICP. Autopercepção do handicap em deficientes auditivos adultos e idosos. Rev CEFAC.1999;1(1):54-63.

5. Almeida K. O processo de reabilitação audiológica do deficiente auditivo idoso. In: Marquesan IQ, Bolaffi C, Gomes ICD, Zorzi JL, organizadores. Tópicos em fonoaudiologia 1995. São Paulo: Lovise; 1995. p. 429-41.

6. Marques ACO, Polato D, Mello JM, Vieira LF. Programa de reabilitação auditiva ao idoso portador de presbiacusia. J Bras Fonoaudiol. 2002;13(3):274-8.

7. Ruschel CV, Carvalho CR, Guarinello AC. A eficiência de um programa de reabilitação audiológica em idosos com presbiacusia e seus familiares. Rev Soc Bras Fonoaudiol. 2007;12(2):92-8.

8. Souza AEN, Russo ICP. Um programa de reabilitação audiológica para idosos, novos usuários de aparelho de amplificação sonora individual. Pró-Fono. 1998;10(2):16-22.

9. Almeida K, Russo ICP, Campos CAH. Indicação, seleção e adaptação de próteses auditivas: princípios. In: Almeida K, Iorio MCM. Próteses auditivas: fundamentos teóricos e aplicações clínicas. 2a ed. São Paulo: Lovise; c2003. p. 35-53.
10. Quintero SM, Marotta RMB, Marone SAM. Avaliação do processamento auditivo de indivíduos idosos com e sem presbiacusia por meio do teste de reconhecimento de dissílabos em tarefa dicótica - SSW. Rev Bras Otorrinolaringol. 2002;68(1)28-33.

11. Modelli MFCG, Bevilacqua MC. Estudo do perfil audiológico dos pacientes adultos e idosos do HRAC, Bauru-USP: subsídios para uma política de intervenção. Fono Atual. 2003;6(25):29-38.

12. Carvalho CRS, Reia AS, Jacobina GS, Silva VCM. Maturidade e envelhecimento: um enfoque fonoaudiológico. Fono Atual. 2003;6(24):4-9.

13. Guarinello AC, Cruz MCM. O perfil dos idosos protetizados na Clínica de Fonoaudiologia da Universidade Tuiuti do Paraná. Fono Atual. 2006;8(35):59-64.

14. Jennings MB, Richert FR. Hearing Aids, Hearing Assistive Technologies, and Rehabilitation Services: a rehabilitative approach to hearing loss in aging. Geriatrics Aging. 2006;9(10):708-11.

15. Domingues MA, Derntl AM, Ourique SAM. Fonoaudiologia em geriatria: identificando o universo do idoso. Mapa Mínimo de Relações: adaptações de um instrumento gráfico para identificar a rede de suporte social do idoso. Fono Atual. 2002;5(20):21-30.

16. Taylor KS. Effects of group composition in Audiologic Rehabilitation Programs for hearing impaired elderly [Internet]. [up to date 2002 Oct 13]. Audiology Online; c2009 [cited 2008 Oct 12]. Available from: http://www.audiologyonline.com/articles/article_detail.asp?article_ id $=498$. 
Anexo 1. Protocolo de entrevista inicial

Data _ _ _ _ _ _

Nome:

Idade: anos

Data de nascimento: ___ _ _ _

Grau da perda:

Orelha direita: ( ) leve ( ) moderada ( ) severa ( ) profunda

Orelha esquerda: ( ) leve ( ) moderada ( ) severa ( ) profunda

Protetização: ( ) orelha direita ( ) orelha esquerda ( ) bilateral

Já era usuário(a): ( ) não ( ) sim

Se sim: Qual modelo/ Quanto tempo?Qual orelha?

Modelo do AASI: ( ) retroauricular ( ) intra canal ( ) intra conduto

Fonoaudióloga:

Entrevista inicial

Relatos do paciente:

Quanto à perda:

Há quanto tempo:

Causa:

Diagnóstico:

Casos de surdez na família:

Quanto ao relacionamento familiar:

\section{Quanto ao estado emocional:}

\section{Privações decorrentes da perda auditiva:}

\section{Quanto à vida social:}

\section{Quanto à vida profissional/ ocupação:}

Maiores dificuldades (ambientes/ locais): 
Expectativas quanto ao uso do AASI:

Modelo dos aparelhos, estado, descrições, habilidade de manuseio, etc.:

Faz uso de técnicas de apoio como leitura labial:

Exames apresentados e/ou solicitados:

Observações do terapeuta: 